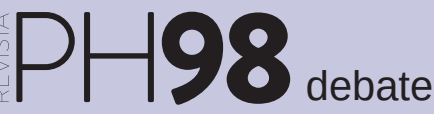

a debate ¿Hay patrimonio sin comunidad? Despoblamiento, turistificación y patrimonio cultural

| coordina Jaime Jover Báez

\title{
Patrimonio, territorio y turismo: una compleja ecuación
}

\author{
Jaime Jover Báez | Centro de Estudios Geográficos, Universidade de Lisboa \\ URL de la contribución <www.iaph.es/revistaph/index.php/revistaph/article/view/4515>
}

Comunidad tiene diferentes acepciones, hasta ocho según el diccionario de la Real Academia, siendo la palabra que más tiene de todas las que conforman este debate. Cuando me propusieron coordinar esta sección con un título tan ecléctico, me atrajo el hecho de tener que acotar conceptos como despoblamiento o turistificación, o abordar la articulación entre comunidad y patrimonio ${ }^{1}$. No obstante, la complejidad de esta tarea excede de largo los límites de la sección, por eso se plantean unas reflexiones generales sobre un tema de mayor calado teórico, amén de algunas propuestas, tratando de ser lo más didáctico posible y estimulando futuros debates y líneas de investigación. Coincidiendo con Vergara-Muñoz y Martínez-Monedero (pp. 327-328), los problemas que no se definen con precisión, o se simplifican en exceso, son difícilmente resolubles, de ahí estas previsiones iniciales. También cabe advertir que se han recibido 25 contribuciones, por lo que he entrado a debatir solamente algunos aspectos, ya que hacerlo con todos supondría una tarea ingente por su calidad y diversidad. Aprovecho esta introducción para agradecer a todas las personas y colectivos que han participado y enriquecido el debate.

En todas esas acepciones de comunidad hay una característica común -valga la redundancia-: la existencia de un conjunto de personas que comparten intereses comunes, normas (acuerdos políticos y económicos, según la academia) y/o un mismo territorio. Una comunidad es un colectivo, un grupo social que se distingue por una serie de rasgos y que es altamente dinámico, está siempre en construcción, como apuntan Eliseo Martínez, Jaime Escribano y José Vicente Pérez (pp. 380-381). Una aldea de apenas treinta habitantes es una comunidad, al igual que un distrito urbano donde viven miles de personas, o cualquier grupo que comparta una misma identidad, teniendo en cuenta que éstas rara vez serán totalmente homogéneas. A excepción de sociedades muy pequeñas, siempre habrá diferencias en el seno de toda comunidad, de clase, género, raza, creencias religiosas, etcétera, lo que configura un marco donde se superponen intereses encontrados con otros comunes. Así, las relaciones sociales o la forma de vertebrar políticamente cada comunidad en cada caso son muy distintas. De hecho, para gestionar esas diferencias existe la política como espacio de disenso (RANCIÈRE, 2000). En contextos democráticos, la sociedad nace con la política -otra cuestión sería la calidad de tales contextos, que da para otro debate-.

El despoblamiento, o los paisajes de la despoblación, como los denomina Juan Ignacio Plaza Gutiérrez (pp. 334-335), son el resultado de procesos socio-económicos y decisiones políticas de distinta índole sobre los territorios. Normalmente se asocia a la pérdida de población en el mundo rural, un asunto que es recurrente en los últimos tiempos, si bien no es novedoso: las ciudades no han parado de crecer desde mediado el siglo XX a costa de personas procedentes de espacios rurales en busca de oportunidades. Otro tema interesante es la despoblación en zonas urbanas, sensiblemente en los centros históricos, que comparte temporalidad con el éxodo rural y, en el caso español, la ola migratoria hacia Europa. Desde mediados del siglo XX, amplias zonas centrales de las ciudades comenzaron a perder población en detrimento de otras áreas urbanas, y las personas que se quedaban habitaban sectores cada vez más abandonados y marginados. Es decir, nos encontramos ante dos fenómenos de despoblamiento que comenzaron a la par en el campo y en la ciudad, si bien tuvieron una evolución distinta. El denominador común fue la explosión o revolución urbana, usando el concepto de Lefebvre (1972), esto es, el fuerte carácter urbano que toma la vida en las sociedades occidentales en un contexto de producción de la ciudad moderna favorecida por la concentración de actividades y servicios y el desarrollo de las infraestruc- 


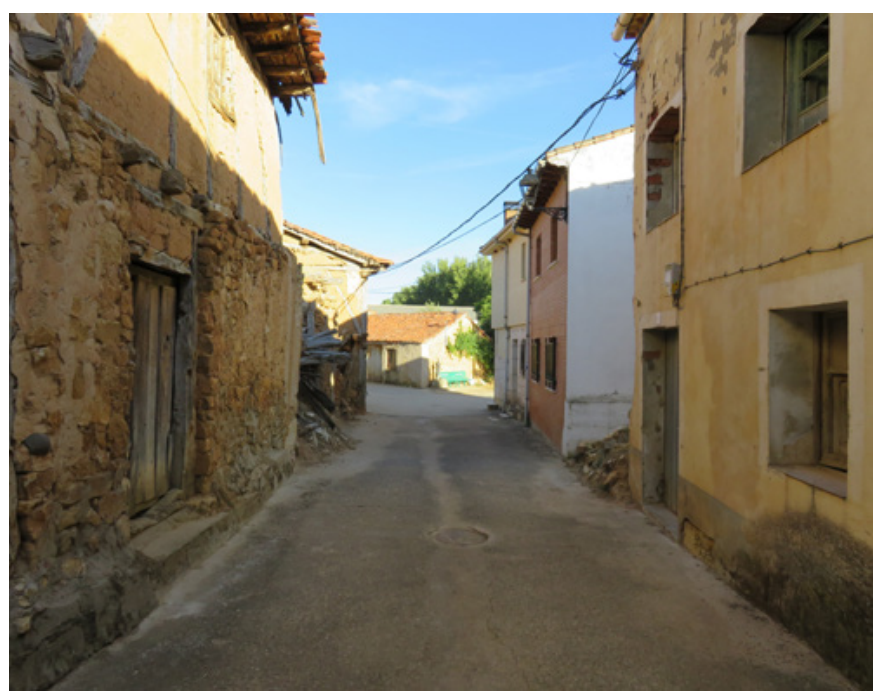

Uno de los muchos paisajes de la despoblación en España | foto Jaime Jover Báez

turas en la transición de economías primarias y secundarias a otras donde el sector servicios es predominante.

Una de las áreas que más ha crecido dentro de ese sector es el turismo. La actividad económica relacionada con viajar por motivos de ocio se etiqueta como cultural cuando aparece el patrimonio en la ecuación. El crecimiento de este tipo de turismo ha coincidido, desde los noventa, con la consolidación de la sensibilidad por otras miradas patrimoniales especialmente a escala internacional, donde se aprecian valores culturales más allá de los arquitectónicos y artísticos (GONZÁLEZVARAS, 1999). Derivado de un modelo turístico que fomenta un aumento aparentemente ilimitado de la actividad, aparece el concepto turistización, primero vinculado a destinos costeros (BLÁZQUEZ; MURRAY, 2010), y recientemente en contextos urbanos. Su utilización ha sido intercambiable con turistificación, haciendo referencia a los procesos que se desencadenan por un incremento virulento del turismo sobre un espacio determinado, impactando en la vida cotidiana de la población local. Entre las consecuencias estarían la transformación del tejido social y comercial, el difícil acceso a la vivienda y al disfrute de los espacios públicos o a esa misma cultura local que se vende en mercados turísti- cos. Tratando de comprender tales efectos, también se ha acuñado el concepto sobreturismo, u overtourism en inglés, que se ha vinculado al caso de Venecia especialmente (SERAPHIN; SHEERAN; PILATO, 2018), sobre el que también reflexiona Patricia Alonso Arroba (pp. 356358). En cualquier caso, de momento estos procesos urbanos se han observado sensiblemente en las ciudades del sur de Europa y en algunas metrópolis globales como Londres o París.

Si la despoblación y el aumento del turismo tienen un punto de partida próximo en el tiempo, sus trayectorias han sido antagónicas. De hecho, el crecimiento de destinos turísticos costeros primero, y urbanos después, ha contribuido a abrir la brecha campo-ciudad. Mientras en el mundo rural ha continuado el goteo poblacional hacia las ciudades, la demografía de los centros urbanos se ha invertido, especialmente en las principales capitales. Ahora bien, esta recuperación de efectivos en los centros urbanos ha sido, por lo general, profundamente injusta, en tanto que ha supuesto la expulsión de las capas de población con menores recursos que se habían quedado -o habían sido segregadas- en tales espacios. La teoría de la gentrificación ha explicado el desplazamiento de unas personas y su sustitución por otras con mayor poder adquisitivo, centrándose al mismo tiempo en explorar cómo la revalorización del precio del suelo y de los inmuebles en espacios concretos -como los centros históricos- han generado excedentes monetarios que se han capitalizado por el sector inmobiliario, bancario y de la construcción (SMITH, 2012). Ello ha sido facilitado en una mayoría de casos mediante distintas estrategias por las instituciones públicas, lo que termina de configurar un proceso abiertamente arbitrario. Entre ellas se encuentra el uso de la cultura y del arte, también aquel fuera de los circuitos habituales -como el arte callejero-, que como estudiara Zukin (1995) puede suponer en ocasiones una primera fase de la gentrificación. Esto es particularmente relevante en barrios próximos a sectores históricos consolidados, como Lagunillas en Málaga, caso que menciona Sergio Reyes Corredera (pp. 359-360), y que viene sufriendo fuertes tensiones especulativas. 
a debate ¿Hay patrimonio sin comunidad? Despoblamiento, turistificación y patrimonio cultural

| coordina Jaime Jover Báez

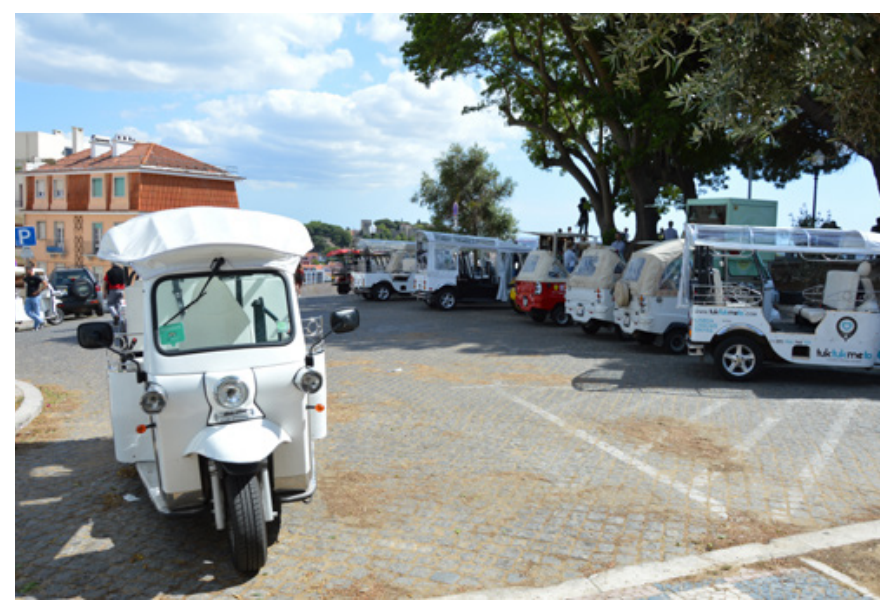

Mirador de Gracia, Lisboa. Los carritos-taxi, 'tuk-tuk', ofrecen visitas turísticas por toda la ciudad | foto Jaime Jover Báez

Las últimas tesis apuntan a que, en algunas ciudades, la turistización se estaría complementando con procesos de gentrificación (DÍAZ PARRA; JOVER, 2019), haciendo cada vez más inaccesible habitar en los centros históricos. Eugenio Rodríguez Castillo (pp. 352-353) sugiere que eso podría acontecer en los casos de úbeda y Baeza, mientras que Lourdes Royo Naranjo (pp. 382385) advierte de los efectos en el centro de Málaga, entre ellos la desafección en términos identitarios que la conversión de este espacio urbano en un escenario turístico provoca entre los malagueños. Ante los rápidos cambios a causa de la turistización, diferentes asociaciones y colectivos han comenzado a organizarse para denunciar los defectos del actual modelo turístico y reivindicar el derecho a la ciudad de las comunidades locales en varias ciudades (JOVER; BERRAQUERO DÍAZ; BARRERO RESCALVO et. ál., 2018). Para cerrar el debate en torno al turismo, Carmen Reimóndez Becerra (pp. 377-379) pone en relación el crecimiento de la turismofobia con la puesta en valor del patrimonio. Más allá de la inexistencia de evidencias empíricas que soporten dicha afirmación, conviene realizar una aclaración. La turismofobia fue empleada por primera vez para designar una etapa de antagonismo entre residentes y visitantes en destinos turísticos estancados (DONAIRE, 2008; YANES, 2017). Sin embargo, desde 2017, los principales medios de comunicación han utilizado el neologismo para enfatizar actitudes anti-turísticas, de rechazo e incluso aversión irracional, siguiendo la propia definición de fobia de la Real Academia. Como han documentado Huete y Mantecón (2018), con ello se ha construido un antagonista, aunque no está fundamentado en el desencuentro entre los intereses de residentes y turistas, sino en una orientación política que apunta hacia la organización social crítica con el turismo. Esta maniobra tendría una finalidad doble. Por un lado, se estaría polarizando el debate en torno a los posibles efectos del modelo turístico en determinados destinos urbanos, reduciendo las posiciones a una dicotomía (a favor o en contra) y deslegitimando la movilización ciudadana. Por otro lado, y como consecuencia de la anterior, se estaría desviando la atención del fondo del asunto, que es precisamente saber el grado de impacto de aquel modelo turístico en los entornos urbanos.

¿De qué forma se entrelaza todo esto con el patrimonio? En el caso concreto de los centros históricos, la transformación en espacios cada vez más exclusivos estaría desequilibrando la diversidad de sus actividades económicas, culturales y sociales, además de hacer más complicado residir en ellos. A la gentrificación que habían sufrido o vienen sufriendo barrios históricos, y que eleva los precios de todo tipo de bienes, se ha añadido la irrupción de las plataformas digitales de alquiler turístico, amparadas en una supuesta economía colaborativa. Esto ha provocado, entre otras cuestiones, una reducción en la oferta de vivienda en los barrios centrales y, por tanto, un incremento todavía mayor de los precios, sensiblemente los arrendamientos urbanos. El incremento de este tipo de alojamientos turísticos, que todavía parece que genera más beneficios en este mercado que en el de arrendamiento tradicional, es posible debido al incensaste crecimiento del turismo. De ahí que aquellas personas que puedan asentarse en la actualidad en los centros históricos tengan normalmente una capacidad económica por encima de la media de la ciudad. Para frenar estas situaciones hace falta la intervención del sector público, tanto en materia turística, como -especialmente por su sensibilidad-en materia de vivienda. Aquí cabe proponer la rehabilitación de 
edificios para alquiler social o, como apunta Alejandra González Biffis (pp. 322-324) en el caso de Montevideo, los sistemas de cooperativas de vivienda. En cualquier caso, las soluciones son urgentes debido a que en estos espacios se estarían desmantelando progresivamente algunas de las comunidades más vulnerables, de la misma forma que el despoblamiento amenaza la pervivencia de las sociedades rurales y, en extensión, de su patrimonio. Para tratar de comprender mejor cómo se engranan estos procesos es preciso traer a colación otro: la patrimonialización.

Entender como patrimonio determinadas expresiones culturales no ocurre de la noche a la mañana. Al contrario, se trata de una trayectoria por la que un grupo social ha comprendido que aquellas tienen significado por ser parte de su identidad, de su memoria, y tienen un arraigo que ayuda a explicar el carácter del colectivo. El patrimonio es una construcción social (PRATS, 1997), y precisamente por eso la teoría patrimonial debería superar el debate binario entre patrimonio material e inmaterial. Como señala Harrison (2010: 10), "para cada objeto patrimonial tangible hay también un patrimonio intangible que lo envuelve: el lenguaje que usamos para describirlo, por ejemplo". Con fines de identificación, catalogación o gestión tiene sentido establecer categorías, y todavía más si atendemos al componente de seguridad, como recuerda Olivia Cachafeiro Bernal (pp. 349-351). Sin embargo, a la hora de estudiarlo y de entenderlo, el patrimonio no existe en sí mismo, su valor lo adquiere en el seno de una sociedad, por eso es siempre inmaterial. Los valores materiales -los componentes físicos que constituyen una obra, o el sentido de la misma- tienen una elevada importancia, y en su valoración cabe establecer criterios objetivos. Sin embargo, el significado de esas expresiones culturales, lo que legitima su propia existencia, viene configurado por su interiorización y lo que representa para las comunidades en cuyo seno se han creado y desarrollado, sin olvidar que éstas son siempre heterogéneas (QUINTERO MORÓN; SÁNCHEZ CARRETERO, 2017). El patrimonio debe entenderse de forma integral: la patrimonialización siempre requiere de los colectivos.

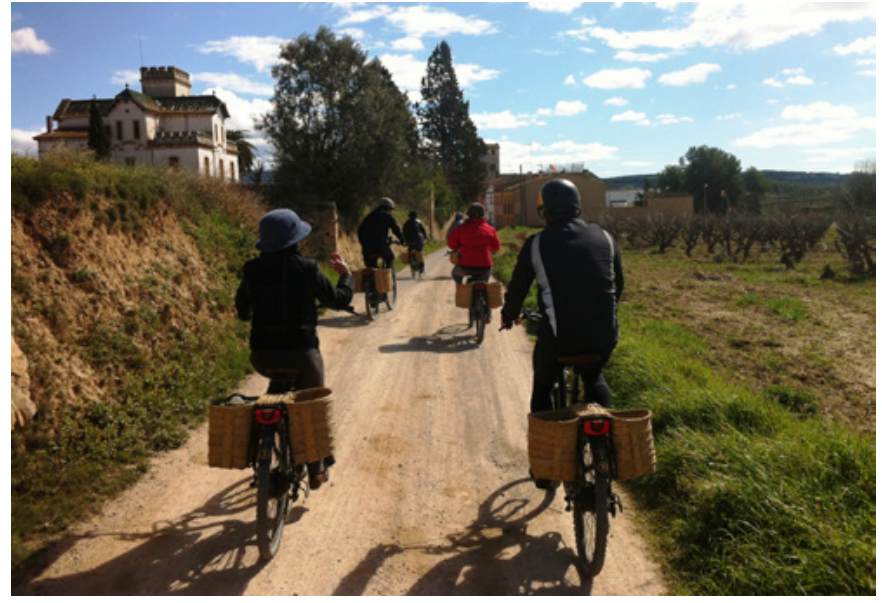

Ruta enoturística en burricleta a la bodega Albet i Noya (Sant Pau d'Ordal, Barcelona) | foto Turisme Subirats

Una cuestión bien distinta es cómo se desenvuelve la patrimonialización y quién tiene el poder para ejercerla. Desde los estudios críticos patrimoniales se ha puesto énfasis en el patrimonio como herramienta de control social y legitimación de un orden presente a través del pasado, donde destaca el trabajo de Lowenthal (1998). Más recientemente, Smith (2006) ha teorizado sobre los discursos autorizados del patrimonio para referirse a la extensa lista de expertos y técnicos que tienen la potestad, en una ciudad, en un país o en el Comité del Patrimonio Mundial, de decidir qué es y qué no es patrimonio. Como proceso colectivo que configura una relación social, el patrimonio condensa relaciones de poder que son susceptibles de ser apropiadas por aquellas personas o grupos que lo detentan para imponer su visión del mundo -cada una, además, con unas formas diferente a la hora de conservarlo-. La patrimonialización es siempre política y prueba de ello es que, desde su origen, ha estado controlada y auspiciada por los estados, siendo clave en la conformación de las culturas nacionales, como comenta Juan Antonio Bermejo (pp. 343345). El patrimonio ha sido una pieza fundamental en la consolidación de los estados-nación modernos, seleccionando aquellos pasajes y elementos de la historia que más interesaban. Además, en la patrimonialización siempre media una autoridad, la diferencia en los sistemas democráticos -donde los problemas se resuelven a 
a debate ¿Hay patrimonio sin comunidad? Despoblamiento, turistificación y patrimonio cultural

| coordina Jaime Jover Báez

través de la política-, es que no hay una única patrimonialización -aquella que hacen las instituciones, a veces referida como de arriba-abajo-. Aunque esta continúa siendo la más poderosa, el proceso se ha abierto y a día de hoy existen ejemplos de patrimonializaciones desde abajo -en plural, porque son múltiples los caminos-, como el que reivindica a través de los saberes transmitidos oralmente y el respeto por el entorno la Comunidad Aldea El Calabacino (pp. 341-342). Al mismo tiempo, el auge que ha experimentado el turismo ha llevado a una transformación de los objetivos iniciales de esta patrimonialización oficial, donde gana peso la cultura como recurso económico. La mercantilización de los centros históricos para la generación de plusvalías apropiadas por el sector turístico es, posiblemente, el mejor ejemplo, como explica con claridad el Grupo de Estudios Antropológicos 'La Corrala' en Granada (pp. 331-333).

Con el auge del turismo cultural, las políticas culturales se han subordinado a los procesos de acumulación, buscando la rentabilidad. El patrimonio es una actividad económica en la que, como estudia Franquesa (2010: 42), existe una "ideología del patrimonio por la que se ocultan el carácter productivo y la relación con el mercado de tales procesos" de patrimonialización. Los dis-

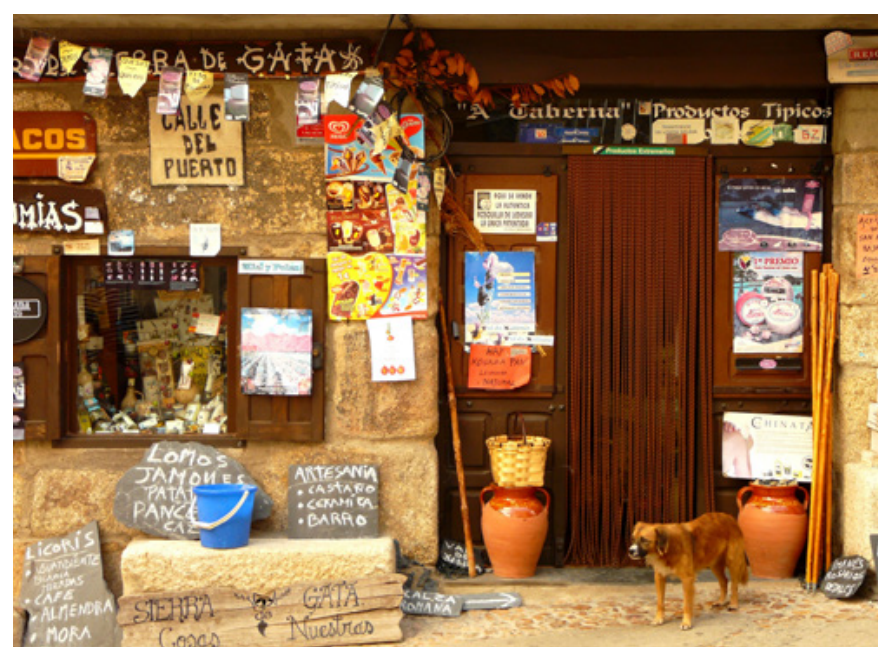

Tienda y perro en San Martín de Trevejo (Sierra de Gata), Cáceres | foto Miguel Ángel Fernández Bravo cursos que se imponen sobre el concepto patrimonio se cubren con un velo que distrae de su sentido económico, desarmando su potencialidad crítica (BERMEJO BARRERA, 2007). En la expansión constante de la economía capitalista, todo es susceptible de convertirse en mercancía, es decir, todo tiene un valor de cambio, incluidas las catedrales o los museos, si bien hace falta crear la apariencia de que esto no es así. Franquesa (ibíd.) explica este proceso, y concluye que el sistema económico necesita producir elementos patrimoniales para continuar acumulando capital, mientras que la oposición a la mercantilización también genera nuevas demandas patrimoniales en forma de resistencia social, aunque estas puedan terminar por incorporarse a la propia expansión del mercado. Así, prácticas y discursos patrimoniales que surgieron como oposición o defensa a dicha expansión son susceptibles de transformarse en aquello diametralmente opuesto a su finalidad original. Por ejemplo, el movimiento vecinal del barrio Yungay de Santiago de Chile, que consiguió frenar el avance de la edificación en altura a través de la reivindicación de su herencia urbana y cultural, consiguiendo la declaración de zona típica -el equivalente a nuestros conjuntos históricos-, la misma que ahora convierte al barrio en atractivo para la inversión -de otra forma diferente, más ligado al desarrollo turístico- y amenaza con expulsar a aquellos vecinos (URIBE CARRASCO, 2014).

De la misma manera, la patrimonialización institucional sometida a los designios del mercado configura el carácter conflictual del patrimonio. Por ejemplo, Morell (2010) estudia la incursión en circuitos turísticos de un barrio obrero del centro histórico de Palma de Mallorca, cuyos habitantes, que habían dado forma a tal carácter que sostiene su promoción, habían sido expulsados en los años previos. Por su parte, Hyra (2017) añade el componente racial en su estudio en Shaw, Washington D.C., donde la cultura y el pasado de un barrio de clase trabajadora afroamericana se manufactura para obtener un atractivo que se capitaliza en el mercado inmobiliario. Ambos casos ilustran una doble desposesión de las comunidades locales: la mercantilización de parte de su cultura y la expulsión de sus barrios donde habían gene- 
rado y desarrollado ésta. Sin embargo, las formas de resistencia no siempre se articulan a través de discursos patrimoniales, como relata María Jesús Sacristán (pp. 368-371) en la Colonia del Tercio y Terol en Madrid, aunque en los últimos años han ganado fuerza conforme ha avanzado la idea de patrimonio territorial. Este concepto, que vincula patrimonio con el territorio y las poblaciones que lo habitan y lo configuran, es causa y consecuencia de esa apertura de la patrimonialización -una suerte de democratización-, y está sirviendo de base a nuevas investigaciones con otras perspectivas sobre el tema, como la del paisaje (SILVA PÉREZ; FERNÁNDEZ SALINAS, 2017). En este sentido, son interesantes los estudios que sugieren visiones de conjunto sobre el patrimonio, como hace José Navarro Pedreño (pp. 320321) en el Palmeral de Elche, lo que además permite situar con más facilidad estos debates con respecto a otros sobre urbanismo o turismo.

Pero el conflicto patrimonial no siempre se refiere a barrios, o no solamente, como sucede en el caso que cuenta Mauricio Lorca en Potrerillos (pp. 338-340), en la región chilena de Atacama, entre los antiguos habitantes vinculados a la mina y los intereses de la empresa minera. La tensión sobre el patrimonio también puede desarrollarse sobre bienes culturales reconocidos mundialmente. Sirva de ejemplo la interpretación de la historia islámica que hace la jerarquía católica cordobesa sobre la Mezquita-Catedral, en la que se infravalora todo aquello que tiene que ver con el pasado musulmán del templo. El monumento trasciende a la propia Iglesia, y aunque ésta tenga el monopolio de su interpretación in situ, en Córdoba todavía existe la conciencia sobre la potencia del templo como parte del legado andalusí (JOVER; ROSA, 2017). Agudo Torrico (2012) señala que la construcción de los discursos sobre los bienes culturales es siempre selectiva -al igual que lo es la propia selección de esos bienes, como se ha comentado-, y además, al realizarse desde el presente sobre elementos del pasado, está en permanente revisión. La patrimonialización no es un proceso lineal o plano, sino que está lleno de dimensiones, y puede configurarse como un espacio de contestación de no haber consenso social sobre el elemento y/o las narrativas que lo explican. La pregunta que emerge entonces es: ¿puede haber patrimonio sin un mínimo consenso sobre su significado en la comunidad que lo entiende como tal? Encontrar respuestas a esta compleja pregunta requiere de, como mínimo, otro debate en profundidad.

Volviendo al mundo rural, y siguiendo a Guadalupe Jiménez-Esquinas (pp. 346-348), cabe recalcar que los paisajes de la despoblación no son responsabilidad de las mujeres, como se suele hacer creer. La despoblación, el envejecimiento o la baja natalidad están directamente asociados a la dificultad para encontrar trabajo, a la precariedad laboral en muchos de ellos, o a las dificultades para conciliar con la vida familiar, unas condiciones en la que siempre salen perdiendo las mujeres. Cuando se habla de despoblación del medio rural, con frecuencia se olvida la presencia de un sistema económico y político que condiciona el destino de muchos territorios y sus habitantes. Por ejemplo, el reciente acuerdo comercial firmado entre la UE y Mercosur para eliminar aranceles a las exportaciones desde países de América Latina, y en el que España ha tenido un rol crucial en su consecución (PELLíCER; SÁNCHEZ, 2019), ¿cómo va a afectar a los agricultores y ganadores espa-

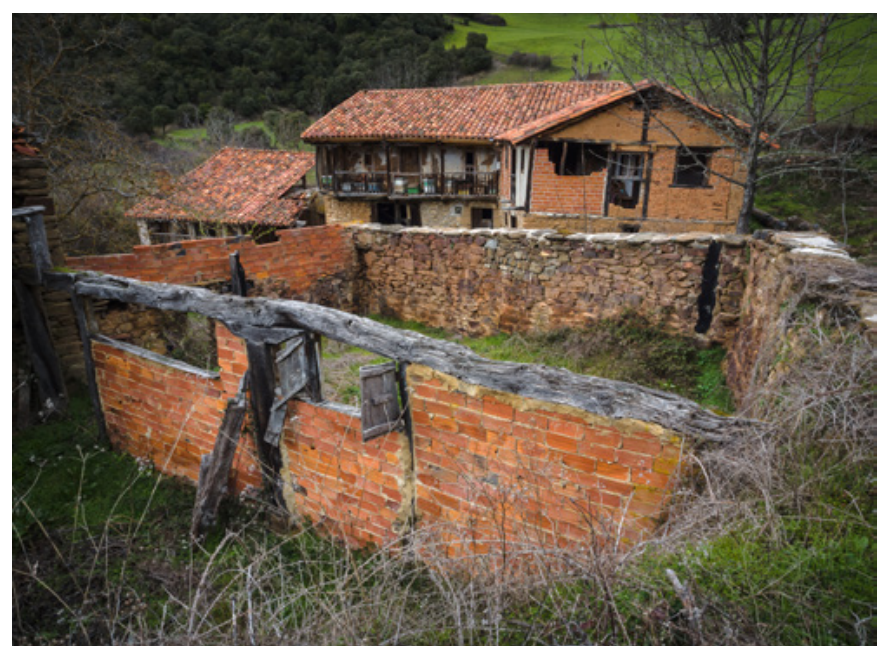

En la locaclidad de Porcieda, Cantabria, no vive nadie desde hace más de 20 años | foto José Luis Canales 
a debate ¿Hay patrimonio sin comunidad? Despoblamiento, turistificación y patrimonio cultural

| coordina Jaime Jover Báez

ñoles? Se asume acríticamente que toda la expansión del mercado es positiva, incluida aquella que elimina barreras comerciales; si bien no parece que se tengan en cuenta las repercusiones para muchas economías locales en la gran mayoría de los municipios del país. ¿A quién benefician estos acuerdos? De nuevo, responder esta pregunta no es una tarea sencilla, y se aleja de nuestros objetivos. Lo que es seguro es que tales aspectos, que normalmente no se tienen en consideración al tratar el tema de la "España vacía", obstaculizan cada vez más el desarrollo personal y profesional en las zonas rurales.

La suerte de mito de la despoblación suele ir de la mano de discursos, como apunta David Pascual (pp. 372-374), que ponen el acento en la falta de futuro en zonas rurales. Algunas contribuciones se resignan a la condición subalterna del mundo rural, lo que en cierto sentido sorprende en un debate organizado desde Andalucía. De la misma manera, parece haber una asunción de las desigualdades territoriales, como si el Estado no fuera una institución que entre sus funciones tuviera la redistribución de la riqueza espacialmente, o la provisión de los servicios públicos independientemente de su rentabilidad -y todavía con mayor responsabilidad allí donde no lo sean-. En esta nueva distribución territorial, comenta Guadalupe Jiménez-Esquinas (pp. 346-348), al mundo rural solo le queda especializarse en proveer ocio para los urbanitas. A esto se asocian los discursos cuasi-románticos del campo como lugar de esparcimiento, en contraposición a la ansiedad de la vida urbana. Se crea un imaginario donde el ámbito rural es un reducto de bienestar y paz, y donde se representa una cultura "auténtica", una especie de tarro de las esencias patrimonial, que al mismo tiempo se convierte en el único atractivo para poder generar recursos a través del turismo. Antes de entrar a valorar esta relación, cabe resaltar que hacer más atractivas las zonas rurales puede provocar procesos de gentrificación rural (PHILLIPS; SMITH, 2018), o como comenta Lidia Díaz Terán de la Asociación Española Contra la Despoblación (pp. 325-326), un incremento de las segundas residencias, que no generan comunidad. Sin embargo, si no fuera por este último fenómeno es posible que el estado de conservación de muchas edificaciones en esos pueblos, villas y aldeas fuese peor de lo que es en la actualidad, según Ana Costa, Miguel Reimao y María Teresa Pérez Cano (pp. 354-355).

Causa y consecuencia de la despoblación es la crisis de funciones del mundo rural que comenta Juan Ignacio Plaza Gutiérrez (pp. 334-335). Sus habitantes solían desempeñarse en diferentes actividades agrarias y ganaderas tradicionales, que ahora se pierden progresivamente, de la misma forma que los bienes culturales eclesiásticos dejan de cumplir su función, como reflexiona Valle Blasco Pérez (pp. 375-376). En este contexto, para varios participantes en el debate, el turismo se convierte en prácticamente el único camino para el desarrollo económico y frenar la despoblación. También son varios, no obstante, los que recuerdan que el turismo no puede ser una panacea, y que es fundamental que su desarrollo sea sostenible y respetuoso con las personas del mundo rural. La ley de mecenazgo para rehabilitar aquel patrimonio arquitectónico en mal estado es una de las ideas recurrentes. Sin menospreciar esta solución, cabe recordar que el derecho de propiedad viene ligado a un deber de conservación por parte de los propietarios, del que las administraciones son garantes. Otra idea es la creación de museos con una gestión activa y centrados en la población a la que sirven, como propone Antonio Bellido Blanco (pp. 329-330). Esto supone recordar las diferencias entre lo que es un museo como buque insignia de las instituciones culturales, y un centro de interpretación. Y ante la falta de recursos, la organización social que relata la Asociación Recartografías en San Agustín, Teruel (pp. 336-337), siempre será una solución para recuperar y mantener viva la memoria de forma activa. La riqueza de estos proyectos es que no buscan poner nada en el mapa, es decir, generar recursos es secundario, la prioridad es el colectivo y su patrimonio.

Resaltar la importancia de las patrimonializaciones por las comunidades locales no es baladí, sobre todo en un contexto de creciente uso mercantil del patrimonio. En el campo de los estudios turísticos se ha investigado sobre la adaptación de la oferta a la demanda en los desti- 
nos de toda índole. Urry (1990) acuñó el concepto de "mirada turística" para referirse a la percepción distorsionada de la realidad que se genera en la experiencia turística. Los visitantes demandan consumir una serie de referentes culturales en el destino, a lo que responde la economía local, adaptándose en pos de obtener beneficios económicos. Con sus prácticas, amplificadas por las nuevas tecnologías, los turistas pueden tener un rol importante sobre qué se entiende por patrimonio, idealizando a las comunidades, reproduciendo estereotipos y en última instancia provocando una distorsión sobre cómo la sociedad se ve a sí misma. En esta configuración es clave el reparto de poder dentro del proceso de patrimonialización entre administraciones, empresarios turísticos y sociedad civil, y para quién y cómo se ejerce su promoción turística. Apostar por el turismo como única solución tiene estos peligros, amén de poder generar procesos de turistización rural, aunque necesitamos más investigaciones que aborden estas relaciones. Además, el incremento del turismo en ámbitos rurales abre la puerta a desequilibrios territoriales, como en la Sierra de Albarracín entre la cabecera y el resto de municipios de la comarca (YUBERO BERNABÉ; GARCÍA HERNÁNDEZ, 2016). Este caso es relevante para discutir la participación de la comunidad en los procesos de patrimonialización y el diseño de la actividad turística. Juan Sevilla (pp. 364-367) vincula patrimonio y desarrollo endógeno y llega a una conclusión similar a la de Alejandro Ruiz (pp. 361-363): la necesidad de acometer planificación y gestión integral. Ello supone una visión amplia de la realidad que conjugue políticas de diferente corte cuyos efectos se superponen, como ocurre entre el turismo y el patrimonio. En términos participativos también supone superar otro hito. La participación de las comunidades tal y como se ha practicado normalmente se articula como una actividad pasiva, y no como un proceso dinámico donde se incorporan las opiniones de todas y es posible llegar a consensos. La dificultad estriba en que son procesos largos y costosos, para la administración y para las personas que invierten su tiempo en ellos, además de estar llenas de contradicciones y contingencias (QUINTERO MORÓN; SÁNCHEZ CARRETERO, 2017).
En definitiva, sin comunidad no hay patrimonio, y para garantizar su pervivencia es preciso que aquella sea plenamente consciente de su memoria y de su cultura. Los esfuerzos han de centrarse en la consolidación de una sociedad civil sólida, con redes de apoyo mutuo y solidaridad entre colectivos en sus territorios. Solo así será posible una mayor sensibilidad con el patrimonio, o lo que es lo mismo, ser conscientes de que somos parte de la patrimonialización. Además de empoderar a las comunidades locales, con este marco las instituciones encontrarían más facilidades para hacer su trabajo, puesto que la patrimonialización institucional no supondría explicar a nadie qué es su patrimonio, sino que actuaría de acompañante ante las demandas sociales, facilitando el proceso en todo aquello que estuviera en su mano. Los profesionales y técnicos del patrimonio debemos ser responsables en este contexto, cuidando a las comunidades en las que nos desenvolvemos, y conscientes del potencial del patrimonio como transformador social. También es clave comprender las contradicciones y riesgos de los procesos de patrimonialización, especialmente aquellos relacionados con actividades económicas, como el turismo. En ocasiones parece mejor que no medie ninguna institución en la patrimonialización, para que la colectividad mantenga su autonomía sobre el bien cultural en cuestión, si bien esto no es siempre posible. Por último, en el campo administrativo, cabría implementar la solidaridad inter-patrimonial entre aquellos bienes que más recursos generan y aquellos que puedan estar en peligro, como muchos en el medio rural. Esta idea, que habría que diseñar con detalle, supone realizar una revisión certera de a quién pertenecen los bienes culturales -abordando con decisión el escándalo de las inmatriculaciones- y con perspectiva de futuro, puesto que la mejor forma de preservar un bien cultural es que sea apropiado por la comunidad, si no con su función original, con otra compatible. 
a debate ¿Hay patrimonio sin comunidad? Despoblamiento, turistificación y patrimonio cultural

| coordina Jaime Jover Báez

\section{NOTA}

1. Las reflexiones de este artículo forman parte del trabajo financiado por la Fundación para la Ciencia y la Tecnología del Gobierno de Portugal, en el ámbito del proyecto SMARTOUR (Ref: PTDC/GES-URB/30551/2017).

\section{BIBLIOGRAFÍA}

- AGUDO TORRICO, J. (2012) Patrimonio etnológico y juego de identidades. Revista Andaluza de Antropología, n. ${ }^{\circ} 2,2012$, pp. 3-24

- BERMEjo BARRERA, J. C. (2007) Moscas en una botella Madrid: Akal, 2007

- BLÁZQUEZ, M.; MURRAY, I. (2010) Una geohistoria de la turistización de las islas Baleares. Periplo Sustentable, n. ${ }^{\circ} 18$, 2010, pp. 69-118

- DÍAZ PARRA, I.; JOVER, J. (2019) Enclaves urbanos de éxito. Transformación urbanística, gentrificación y turismo en la Alameda de Hércules de Sevilla. En GASCA-ZAMORA, J. (ed.) Capital inmobiliario. Producción y transgresión del espacio social en la ciudad neoliberal. México: UNAM, 2019, pp. 337357

- DONAIRE, J. A. (2008) La efervescencia de la 'turismofobia'. Sobre turistas y turismo. Barcelona Metrópolis, $2008<$ https:// ecoplann.wordpress.com/2010/12/02/barcelona-metropolisjose-antonio-donaire-la/> [Consulta: 30/08/2019]

- FRANQUESA, J. (2010) Una aproximación al patrimonio desde la antropología económica: la patrimonialización como guardar. En MÁRMOL, C. DEL; FRIGOLÉ, J.; NAROTZKY, S. Los lindes del patrimonio. Barcelona: Icaria, 2010, pp. 39-60

- GONZÁLEZ-VARAS, I. (1999) Conservación de bienes culturales. Teoría, historia, principios y normas. Madrid: Cátedra, 1999

- HARRISON, R. (2010) What is heritage? En HARRISON, R. (ed.) Understanding the politics of heritage. Manchester: Manchester University Press, 2010, pp. 5-42

- hUete, R.; MANTECón, A. (2018) El auge de la turismofobia ¿hipótesis de investigación o ruido ideológico? Pasos, Revista de Turismo y Patrimonio Cultural, vol. 16, n. ${ }^{0}$ 1, 2018, pp. 9-19

- HYRA, D. (2017) Race, Class, and Politics in the Cappuccino City. Chicago: University of Chicago Press, 2017

- JOVER, J.; ROSA, B. (2017) Patrimonio cultural en disputa: la Mezquita-Catedral de Córdoba. Cuadernos Geográficos, vol. 56, n. ${ }^{\circ} 1,2017$, pp. 322-343

- JOVER, J.; BERRAQUERO DÍAZ, L.; BARRERO RESCALVO, M.; JIMÉNEZ TALAVERA, A. (2018) Turistización y movimientos urbanos de resistencia: experiencias desde Sevilla. En MILANO, C.; MANSILLA, J. (ed.) Ciudad de vacaciones. Barcelona: Pol.len., 2018, pp. 403-437

- LEFEBVRE, H. (1972) La revolución urbana. 1. a ed. 1970. Madrid: Alianza, 1972

- LOWENTHAL, D. (1998) El pasado es un país extraño. Madrid: Akal, 1998

- MORELL, M. (2010) Patrimonio de la clase obrera sin la clase obrera. Etnografía de la gentrificación en Ciutat (Mallorca). En MÁRMOL C. DEL; FRIGOLÉ, J.; NAROTZKY, S. (ed.) Los lindes del patrimonio. Barcelona: Icaria, 2010, pp. 105-125

- PELLÍCER, L.; SÁNCHEZ, A. (2019) La UE y Mercosur logran un acuerdo comercial tras 20 años de negociaciones. El País [en línea], 29 de junio de 2019 <https://elpais.com/ internacional/2019/06/28/actualidad/1561741765 367243. amp.html> [Consulta: 21/07/2019]

- PHILLIPS, M.; SMITH, D. P. (2018) Comparative approaches to gentrification: lessons from the rural. Dialogues in Human Geography, 8(1), 2018, pp. 3-25

- PRATS, L. (1997) Antropología y patrimonio. Barcelona: Ariel, 1997

- QUINTERO MORÓN, V.; SÁNCHEZ CARRETERO, C. (2017) Los verbos de la participación social y sus conjugaciones: contradicciones de un patrimonio democratizador. Revista Andaluza de Antropología, n. ${ }^{\circ}$ 12, 2017, pp. 48-69

- RANCIÈRE, J. (2006) El odio a la democracia. 1. a ed. 2000. Buenos Aires: Amorrortu, 2006

- SERAPHIN, H.; SHEERAN, P.; PILATO, M. (2018) Overtourism and the fall of Venice as a destination. Journal of Destination Marketing \& Management, 9, 2018, pp. 374-376

- SILVA PÉREZ, R.; FERNÁNDEZ SALINAS, V. (2017) EI nuevo paradigma del patrimonio y su consideración con los paisajes: conceptos, métodos y prospectivas. Documents d'Anàlisi Geogràfica, vol. 63, n. ${ }^{\circ}$ 1, 2017, pp. 129-151

- SMITH, L. (2006) Uses of heritage. Nueva York: Routledge, 2006

- SMITH, N. (2012) La nueva frontera urbana. Ciudad revanchista y gentrificación. 1. $^{\text {a }}$ ed. 1996. Madrid: Traficantes de Sueños, 2012

- URIBE CARRASCO, N. (2014) Patrimonialización comunitaria en barrios de Santiago: los casos de las zonas típicas de Viel y Yungay. Apuntes, vol. 27, n. ${ }^{\circ} 1,2014$, pp. 8093 
- URRY, J. (1990) The tourist gaze. Londres: SAGE, 1990

- YANES, S. (2017) Operación turismofobia. CincoDías (El País Economía) [en línea], 15 de agosto de 2017 <https://cincodias.elpais.com/cincodias/2017/08/14/ companias/1502723297_610226.html> [Consulta: 20/08/2019]

- YUBERO BERNABÉ, C.; GARCÍA HERNÁNDEZ, M. (2016) Turismo en Albarracín y Comarca. Acción pública local y dinámica reciente en clave de desarrollo turístico sostenible. Anales de Geografía, vol. 36, n. ${ }^{0} 1,2016$, pp. 173-194

- ZUKIN, S. (1995) The culture of cities. Oxford: Blackwell, 1995 